\title{
Synthesis and Characterization of Nanoporous Monetite Which Can Be Applicable for Drug Carrier
}

\author{
Esmael Salimi and Jafar Javadpour \\ Faculty of Material Science and Engineering, Iran University of Science and Technology, Narmak, Tehran 16846, Iran \\ Correspondence should be addressed to Esmael Salimi, small_salim2005@yahoo.com \\ Received 22 May 2012; Accepted 18 October 2012 \\ Academic Editor: Jun Liu
}

Copyright ( $) 2012$ E. Salimi and J. Javadpour. This is an open access article distributed under the Creative Commons Attribution License, which permits unrestricted use, distribution, and reproduction in any medium, provided the original work is properly cited.

Wormhole-like mesostructured monetite was successfully synthesized using cetyltrimethylammonium bromide $\left(\mathrm{C}_{19} \mathrm{H}_{42} \mathrm{BrN}_{\mathrm{N}}\right.$, $\mathrm{CTAB})$, as a porosity agent. X-ray techniques and FTIR reveal that the crystalline grains consist of highly crystalline pure monetite phase. Monetite rods with diameter around 20-40 nm and length in the range of 50-200 nm were confirmed by FESEM and TEM. Based on $\mathrm{N}_{2}$ adsorption-desorption isotherms investigation, surface area increased up to $31.5 \mathrm{~m}^{2} / \mathrm{g}$ due to the removal of surfactant after calcinations at $400^{\circ} \mathrm{C}$. The results indicate that CTAB can not only affect monetite crystallization but also change particles morphology from plate shape to rod-like.

\section{Introduction}

Monetite's potential as a biomaterial has recently been highlighted by a series of in vitro, animal and human studies in which monetite-based biomaterials have shown promising results as bone substitutes [1-3].

Monetite has a higher solubility than octacalcium phosphate, tricalcium phosphate, and calcium hydroxyapatite in aqueous solutions at the physiological $\mathrm{pH}$ and is considered to exhibit a high in vivo resorbability in comparison to the apatitic cements [3]. This high solubility has been the main stimulus for the current study.

Introduction of nano-sized pores in these materials can not only significantly enhance the total surface area but also promote adsorption of biomolecules and drugs onto the surface of the particles. It can also increase their solubility and resorbability to the high levels [4]. Since the formation of silicate-based mesoporous structure was reported in 1992 [5], it has become one of the most active research area of material science [6-8]. So far, monetite particles have been synthesized via different processing routes $[9,10]$. To our best knowledge, the synthesis of mesoporous monetite has been seldom reported in the literature. In this study, we attempt to achieve the direct crystallization of mesoporous monetite by chemical precipitation method using CTAB as a structure directing agent.

\section{Experimental}

2.1. Materials and Procedure. Calcium chloride $\left(\mathrm{CaCl}_{2}\right.$, Merck Co) and diammonium hydrogen phosphate $\left[\mathrm{KH}_{2} \mathrm{PO}_{4}\right.$, Merck $\left.\mathrm{Co}\right]$ as the $\mathrm{Ca}$ and $\mathrm{P}$ sources and $\mathrm{CTAB}$ as surfactant were used to synthesize nanoporous monetite powders in this study.

In a successful synthesis run to yield only singlephase $\mathrm{CaHPO}_{4}, 4.075 \mathrm{~g}$ potassium dihydrogen phosphate $\left[\mathrm{KH}_{2} \mathrm{PO}_{4}\right]$ and $5 \mathrm{~g}$ CTAB were dissolved in $50 \mathrm{~mL}$ deionized water at room temperature with stirring for $1 \mathrm{hr}$. Subsequently, $5.55 \mathrm{~g} \mathrm{CaCl}_{2}$ in $50 \mathrm{~mL}$ de-ionized water was added dropwise to the solution mixture, yielding a milky suspension, which was refluxed at $120^{\circ} \mathrm{C}$ for $24 \mathrm{~h}$.

The $\mathrm{pH}$ value was adjusted to $\mathrm{pH}=4-5$. The suspension was then transferred into a $100 \mathrm{~mL}$ PTFE-lined autoclave and heated at $90-150^{\circ} \mathrm{C}$ in an oven for a specified time. The precipitate was filtered and washed several times with distilled water to remove contaminated ions and surfactant. Then, it was dried at $100^{\circ} \mathrm{C}$ for $24 \mathrm{~h}$. Calcination of powder was carried out at different temperature (up to $550^{\circ} \mathrm{C}$ ). 


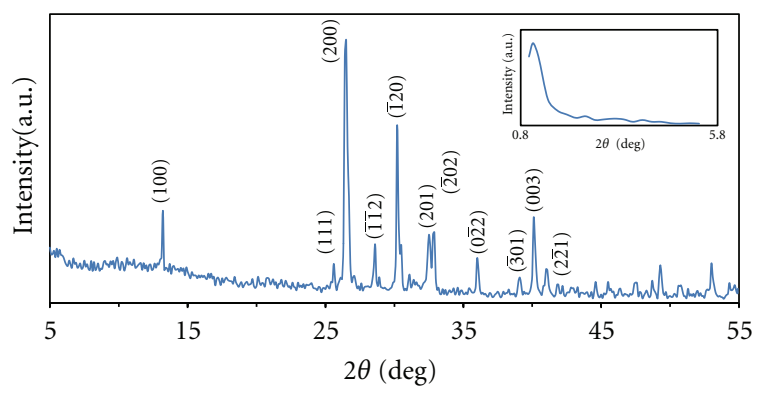

FIGURE 1: WAXRD and LAXRD (inset) pattern of as-dried nanoporous monetite.

2.2. Characterization. The $\mathrm{X}$-ray powder diffraction patterns were recorded on a Philips 1830 diffractometer using $\mathrm{Cu}$ $\mathrm{K} \alpha$ radiation at $40 \mathrm{kV}$ and $40 \mathrm{~mA}$. Nitrogen adsorptiondesorption isotherms of the synthesized samples were measured at $77 \mathrm{~K}$ on Micromeritics model ASAP 2010 sorptometer to determine pore-size distribution and surface area of the samples. Energy dispersive X-ray (EDX) element analysis was carried out on the JEOL 6300F scanning microscope. The morphology of the powders was examined by scanning (SEM, JEOL 6300F) and transmission (TEM, Philips CM120) electron microscopy. The Fourier transform infrared spectra of samples were measured on a DIGILAB FTS 7000 instrument under attenuated total reflection (ATR) mode using a diamond module. TGA (Perkin-Elmer 7 series thermal analysis system) was performed at $10^{\circ} \mathrm{C} / \mathrm{min}$ from room temperature to $800^{\circ} \mathrm{C}$ to determine the thermal behavior of the synthesized monetite.

\section{Results and Discussion}

Figure 1 shows the XRD patterns of the as-dried and calcined monetite. WAXRD patterns (Figure 1) of the nanoparticles consist of narrow peaks with $d$ spacing consistent with well-ordered crystalline monetite. (JCPDS 71-1759). The chemical reaction for the formation of monetite can be simplified as $\mathrm{Ca}^{+2}+\mathrm{H}_{2} \mathrm{PO}_{4}{ }^{-}=\mathrm{CaHPO}_{4}+\mathrm{H}^{+}$.

The peaks within small angle range $\left(2\right.$ theta $\left.1-10^{\circ}\right)$ provide information on the arrangement presented by porous structure [11].

For LAXRD (Figure 1 inset), the pattern of the as-dried sample shows a single intense diffraction peak at $2 \theta$ value of $1.114^{\circ}(d=7.92 \mathrm{~nm})$. The single peak suggested the presence of disordered mesoporous structure inside the sample, such as worm-like mesopores $[11,12]$.

Figures 2(a) and 2(b) show the FTIR spectra of calcium phosphate before and after calcinations. Figure 2(a) slows only the characteristic IR bonds of monetite [13-18].

The wavenumbers and corresponding assignment are represented in Table 1.

The adsorption bonds at $2921 \mathrm{~cm}^{-1}, 1637 \mathrm{~cm}^{-1}$, and $1400 \mathrm{~cm}^{-1}$ are characteristic peaks for $\mu(\mathrm{C}-\mathrm{H}), \delta(\mathrm{N}-\mathrm{H})$, and $\delta(\mathrm{C}-\mathrm{H})$, respectively $[13,18]$, that reveal the presence of surfactant in monetite structure. These results are in accordance with the XRD (Figure 1) description above,
TABLE 1: The wavenumbers and corresponding assignments of monetite.

\begin{tabular}{ll}
\hline $\begin{array}{l}\text { IR monetite } \\
\text { wavenumbers }\left(\mathrm{cm}^{-1}\right)\end{array}$ & Assignments \\
\hline 2921 & C-H stretching [19] \\
2852 & O-H stretching of residual free water \\
3461 & {$[14]$} \\
902 & P-O $(\mathrm{H})$ stretching $[13,19]$ \\
1064 & P-O stretching [14, 19] \\
1130 & H-O-H bending and rotation of \\
1637 & residual free water [14] \\
1400 & P-O-H in plane (bending) [14] \\
530 & O-P-O(H) bending mode [14] \\
583 & \\
1419 & Carbonate (from atmosphere) [15] \\
\hline
\end{tabular}

demonstrating that single-phase and highly crystalline monetite can be obtained with the aid of surfactant as a template, while Figure 2(b) reveals the adsorption bonds for calcium pyrophosphate polycrystalline.

The bonds at $530 \mathrm{~cm}^{-1}$ [19], $1031 \mathrm{~cm}^{-1}[18,19]$, $1139 \mathrm{~cm}^{-1}$ [20], $563 \mathrm{~cm}^{-1}$ [20], and $1074 \mathrm{~cm}^{-1}$ [20] are ascribed to $\mathrm{PO}_{4}{ }^{-3}$ ions, at $1556 \mathrm{~cm}^{-1}$ to $\mathrm{CO}_{4}{ }^{-3}$ ions [18]. A very sharp and intense band appears around $\sim 721 \mathrm{~cm}^{-1}$ due to $\mathrm{P}_{2} \mathrm{O}_{7}{ }^{-4}$ showing the presence of calcium pyrophosphate $\left(\mathrm{Ca}_{2} \mathrm{P}_{2} \mathrm{O}_{7}\right)$ [20], and the band at $\sim 3430 \mathrm{~cm}^{-1}$ is assigned to the bending mode of the $\mathrm{OH}^{-1}$ vibration [13]. The FTIR spectrum shows no adsorption band related to organic molecules. So, it can be concluded that, there is no residual surfactant in the structure after calcinations.

Adsorption-desorption isotherms and pore size distributions of mesoporous monetite calcined at different temperatures are shown in Figure 3. Appropriate calcination temperatures concluded from thermogravimetric analysis. Samples calcined at $200^{\circ} \mathrm{C}, 400^{\circ} \mathrm{C}$, and $470^{\circ} \mathrm{C}$ exhibit a mesoporous materials type IV curve with a hysteresis loop. The BET surface area is calculated to be $31.3 \mathrm{~m}^{2} / \mathrm{g}, 31.5 \mathrm{~m}^{2} / \mathrm{g}$, and $28.8 \mathrm{~m}^{2} / \mathrm{g}$ for samples calcined at $200^{\circ} \mathrm{C}, 400^{\circ} \mathrm{C}$, and $470^{\circ} \mathrm{C}$, respectively.

The low specific is attributed to the formation of mesostructure with thick walls (Figure 4(d)), though the pore volume is high. After calcination at high temperature $\left(>500^{\circ} \mathrm{C}\right)$, due to the conversion of monetite to calcium pyrophosphate (Figure 1), the porous structure is collapsed and the specific surface area decreased to $5.22 \mathrm{~m}^{2} / \mathrm{g}$ as indicated in Figure 3(d). The pore volume was evaluated as $0.99 \mathrm{~cm}^{3} / \mathrm{g}, 0.98 \mathrm{~cm}^{3} / \mathrm{g}$, and $0.3 \mathrm{~cm}^{3} / \mathrm{g}$ for samples calcined at $200^{\circ} \mathrm{C}, 400^{\circ} \mathrm{C}$, and $470^{\circ} \mathrm{C}$, respectively.

Precipitation of calcium phosphate without template is successfully performed by mixing $\mathrm{KH}_{2} \mathrm{PO}_{4}(3 \mathrm{M})$ and $\mathrm{NaOH}$ $(1 \mathrm{M})$ with $\mathrm{CaCl}_{2}(5 \mathrm{M})$ with a $\mathrm{pH}$ sufficient to obtain monetite. 


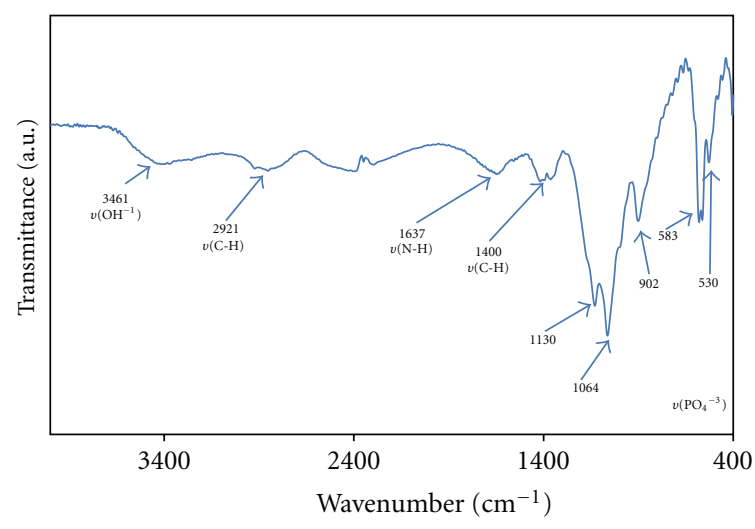

(a)

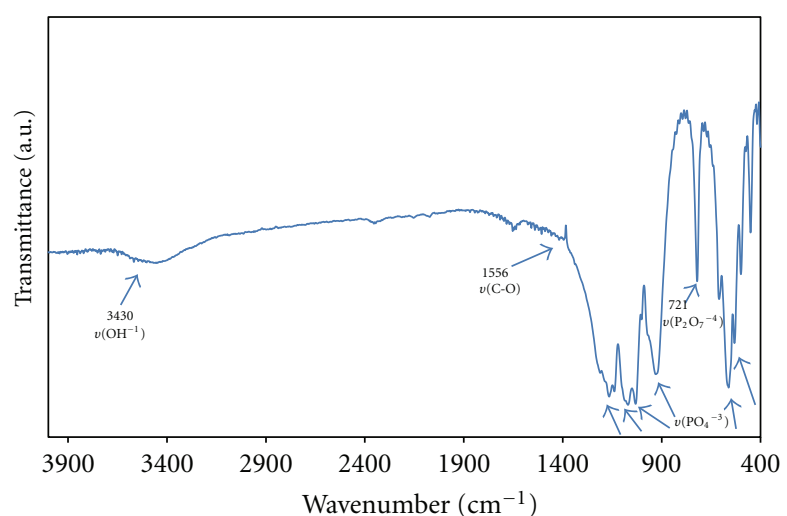

(b)

FIGURE 2: FTIR spectrum of (a) nanoporous monetite and (b) calcium pyrophosphate prepared after calcinations of nanoporous monetite at $550^{\circ} \mathrm{C}$.

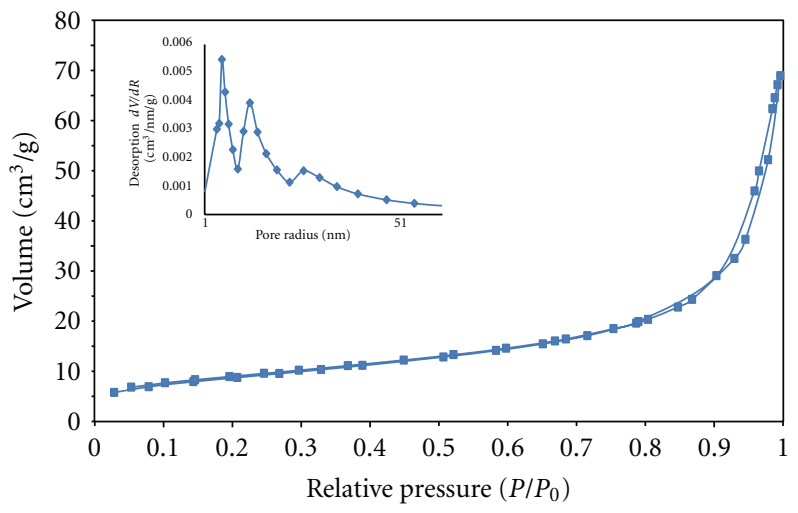

(a)

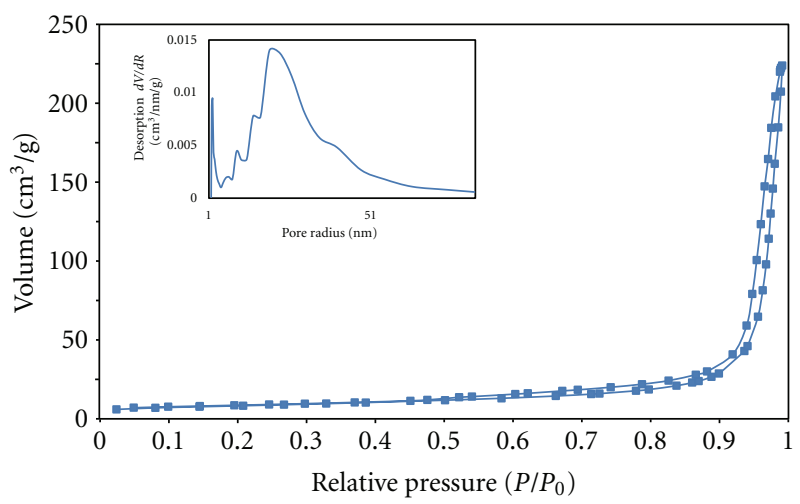

(c)

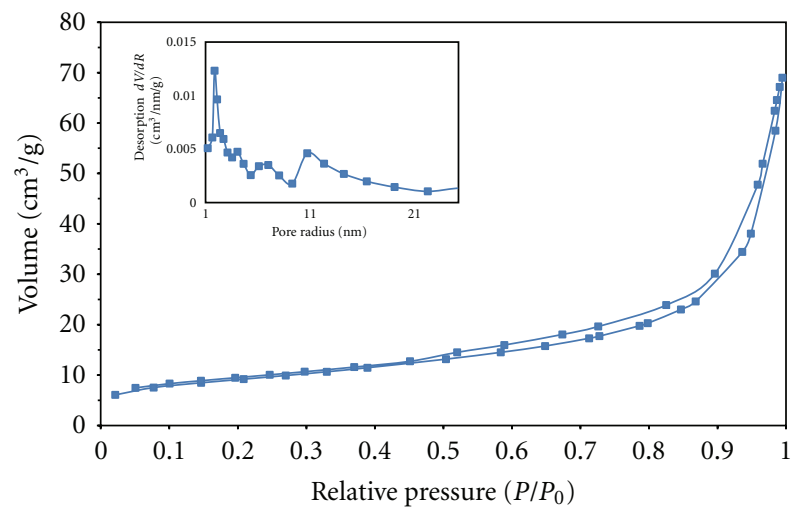

(b)

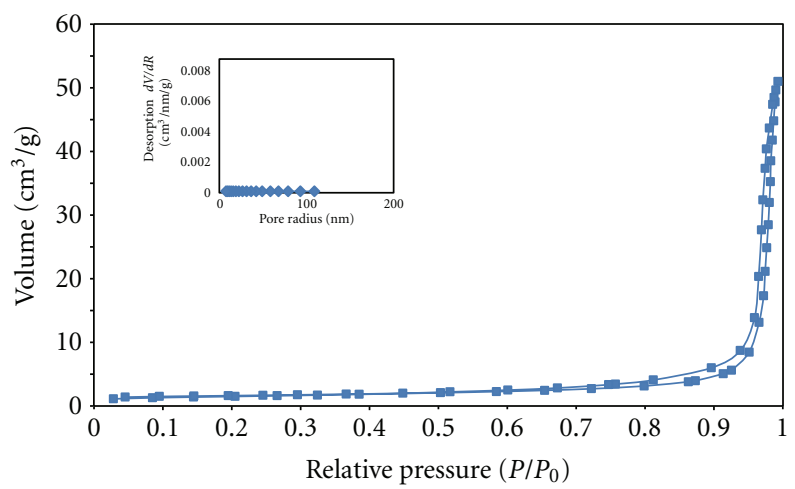

(d)

FIGURE 3: Nitrogen adsorption-desorption isotherms of nanoporous monetite after calcination at (a) $200^{\circ} \mathrm{C}$, (b) $400^{\circ} \mathrm{C}$, (c) $470^{\circ} \mathrm{C}$, and (d) $550^{\circ} \mathrm{C}$.

It can be seen that the monetite prepared without $\mathrm{CTAB}$ (Figures 4(a) and 4(b)) is almost agglomerated plate-shape, with lateral sizes of $2-10 \mu \mathrm{m}$ and thickness of $1-3 \mu \mathrm{m}$.

The TEM micrograph of the prepared nanoporous monetite sample (Figure 4(c)) shows that the synthesized monetite is fairly dispersed nanorods of diameter $20-40 \mathrm{~nm}$ and in the length range of $50-200 \mathrm{~nm}$. It is clear that the morphology and size of monetite can be controlled effectively by using CTAB.

$\mathrm{EDX}$ analysis indicated a $\mathrm{Ca}: \mathrm{P}$ ratio of approximately 1 , characteristic of monetite. A bright cylindrical restrict (not very obvious) can be seen in the center of rods (Figure 4(d)). It seems that it is a hollow space, originated due to the removal of surfactant. The rod-like micelles formed during 


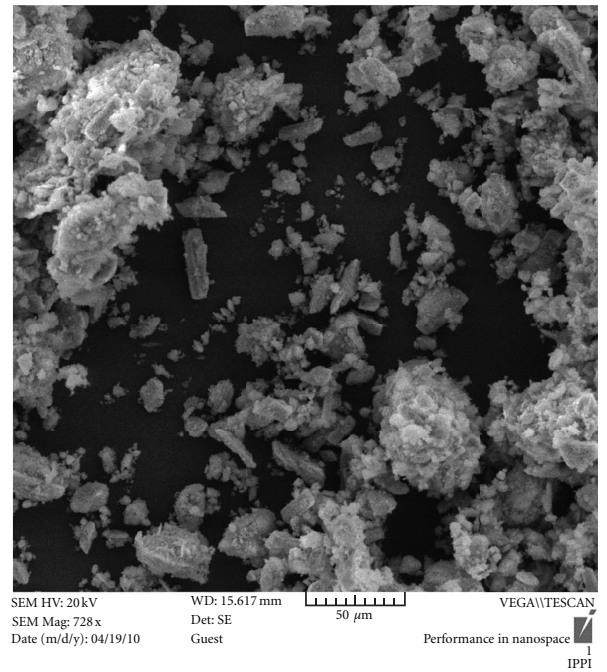

(a)

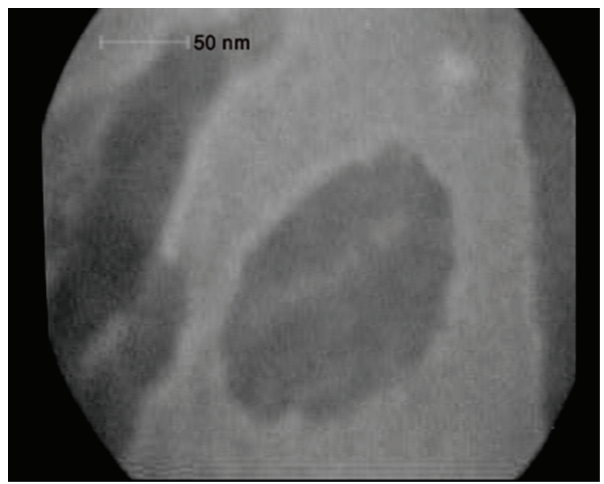

(c)

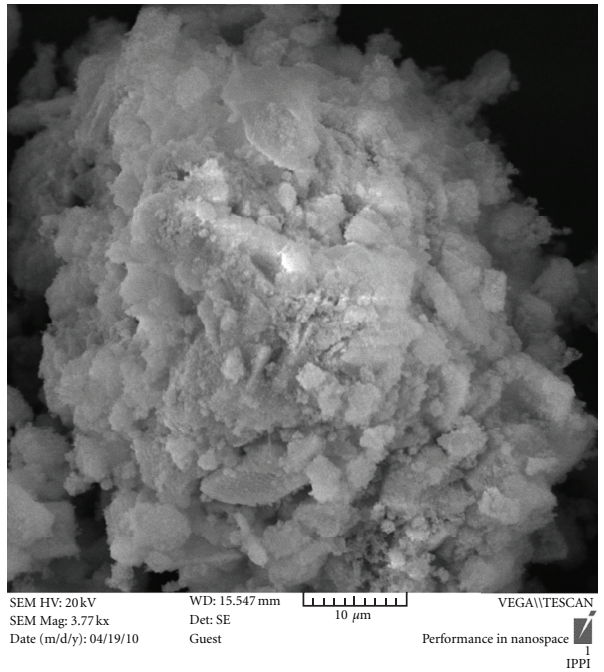

(b)

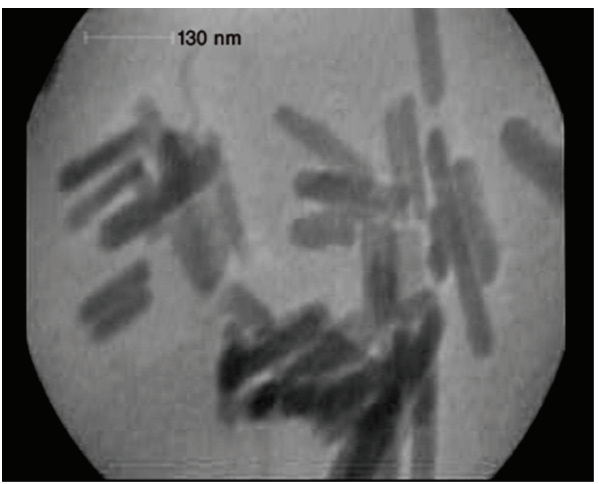

(d)

FIGURE 4: (a) and (b) SEM micrographs of monetite prepared without surfactant; (c) and (d) TEM micrograph of nanoporous monetite.

the synthesis and served as templates. The micelles, not only provide nucleation sites for target materials induced the orientational growth of the monetite particles, but also create nanopores in the structure.

\section{Conclusions}

Monetite particles with mesoporous structure and controlled morphology were successfully synthesized using CTAB as cationic surfactant. A strong association between the $\mathrm{CaHPO}_{4}$ and surfactant molecules throughout the development of the crystal could be responsible for the formation of well-crystallized monetite with rod-like morphology. However, the mesostructured phase was unstable at higher temperature because of the transformation of monetite to calcium pyrophosphate.

\section{Acknowledgment}

Research council of Iran University of Science and Technology (IUST, Iran) is appreciated for the financial support.

\section{References}

[1] U. Gbureck, T. Hölzel, U. Klammert, K. Würzler, F. A. Müller, and J. E. Barralet, "Resorbable dicalcium phosphate bone substitutes prepared by 3D powder printing," Advanced Functional Materials, vol. 17, no. 18, pp. 3940-3945, 2007.

[2] P. Habibovic, U. Gbureck, C. J. Doillon, D. C. Bassett, C. A. van Blitterswijk, and J. E. Barralet, "Osteoconduction and osteoinduction of low-temperature 3D printed bioceramic implants," Biomaterials, vol. 29, no. 7, pp. 944-953, 2008.

[3] F. Tamimi, J. Torres, D. Bassett, J. Barralet, and E. L. Cabarcos, "Resorption of monetite granules in alveolar bone defects in human patients," Biomaterials, vol. 31, no. 10, pp. 2762-2769, 2010.

[4] H. C. Shum, A. Bandyopadhyay, S. Bose, and D. A. Weitz, "Double emulsion droplets as microreactors for synthesis of mesoporous hydroxyapatite," Chemistry of Materials, vol. 21, no. 22, pp. 5548-5555, 2009.

[5] C. T. Kresge, M. E. Leonowicz, W. J. Roth, J. C. Vartuli, and J. S. Beck, "Ordered mesoporous molecular sieves synthesized by a liquid-crystal template mechanism," Nature, vol. 359, no. 6397, pp. 710-712, 1992.

[6] M. Anbia and S. E. Moradi, "Adsorption of naphthalenederived compounds from water by chemically oxidized 
nanoporous carbon," Chemical Engineering Journal, vol. 148, no. 2-3, pp. 452-458, 2009.

[7] M. Anbia and A. Ghaffari, "Adsorption of phenolic compounds from aqueous solutions using carbon nanoporous adsorbent coated with polymer," Applied Surface Science, vol. 255, no. 23, pp. 9487-9492, 2009.

[8] M. Anbia and N. Mohammadi, "A nanoporous adsorbent for removal of furfural from aqueous solutions," Desalination, vol. 249, no. 1, pp. 150-153, 2009.

[9] Y. Guo, Y. Zhou, D. Jia, and H. Tang, "Fabrication and characterization of hydroxycarbonate apatite with mesoporous structure," Microporous and Mesoporous Materials, vol. 118, no. 1-3, pp. 480-488, 2009.

[10] S. Jinawath and P. Sujaridworakun, "Fabrication of porous calcium phosphates," Materials Science and Engineering C, vol. 22, no. 1, pp. 41-46, 2002.

[11] Y. F. Zhao and J. Ma, "Triblock co-polymer templating synthesis of mesostructured hydroxyapatite," Microporous and Mesoporous Materials, vol. 87, no. 2, pp. 110-117, 2005.

[12] H. Guo, F. Ye, and H. Zhang, "Tween-60 mediated synthesis of lamellar hydroxyapatite with worm-like mesopores," Materials Letters, vol. 62, no. 14, pp. 2129-2132, 2008.

[13] Q. Ruan, Y. Zhu, Y. Zeng et al., "Ultrasonic-irradiationassisted oriented assembly of ordered monetite nanosheets stacking," Journal of Physical Chemistry B, vol. 113, no. 4, pp. 1100-1106, 2009.

[14] S. Mandel and A. C. Tas, "Brushite $\left(\mathrm{CaHPO}_{4} \cdot 2 \mathrm{H}_{2} \mathrm{O}\right)$ to octacalcium phosphate $\left(\mathrm{Ca}_{8}\left(\mathrm{HPO}_{4}\right)_{2}\left(\mathrm{PO}_{4}\right)_{4} \cdot 5 \mathrm{H}_{2} \mathrm{O}\right)$ transformation in DMEM solutions at $36.5^{\circ} \mathrm{C}$," Materials Science and Engineering C, vol. 30, no. 2, pp. 245-254, 2010.

[15] A. Lebugle, B. Sallek, and A. Tai Tai, "Surface modification of monetite in water at $37^{\circ} \mathrm{C}$ : characterisation by XPS," Journal of Materials Chemistry, vol. 9, no. 10, pp. 2511-2515, 1999.

[16] A. C. Tas, "Monetite $\left(\mathrm{CaHPO}_{4}\right)$ synthesis in ethanol at room temperature," Journal of the American Ceramic Society, vol. 92, no. 12, pp. 2907-2912, 2009.

[17] E. Fernandez, M. P. Ginebra, M. G. Boltong et al., "Kinetic study of the setting reaction of a calcium phosphate bone cement," Journal of Biomedical Materials Research, vol. 32, pp. 367-374, 1996.

[18] X. Xin-Bo, Z. Xie-Rong, Z. Chun-Li, L. Ping, and F. Yun-Bo, "Influence of hydrothermal temperature on hydroxyapatite coating transformed from monetite on HT-C/C composites by induction heating method," Surface and Coatings Technology, vol. 204, no. 1-2, pp. 115-119, 2009.

[19] P. M. SL Shanthi, M. Ashok, T. Balasubramanian, A. Riyasdeen, and M. A. Akbarsha, "Synthesis and characterization of nano-hydroxyapatite at ambient temperature using cationic surfactant," Materials Letters, vol. 63, no. 24-25, pp. 21232125, 2009.

[20] S. Singh, P. Bhardwaj, V. Singh, S. Aggarwal, and U. K. Mandal, "Synthesis of nanocrystalline calcium phosphate in microemulsion-effect of nature of surfactants," Journal of Colloid and Interface Science, vol. 319, no. 1, pp. 322-329, 2008. 

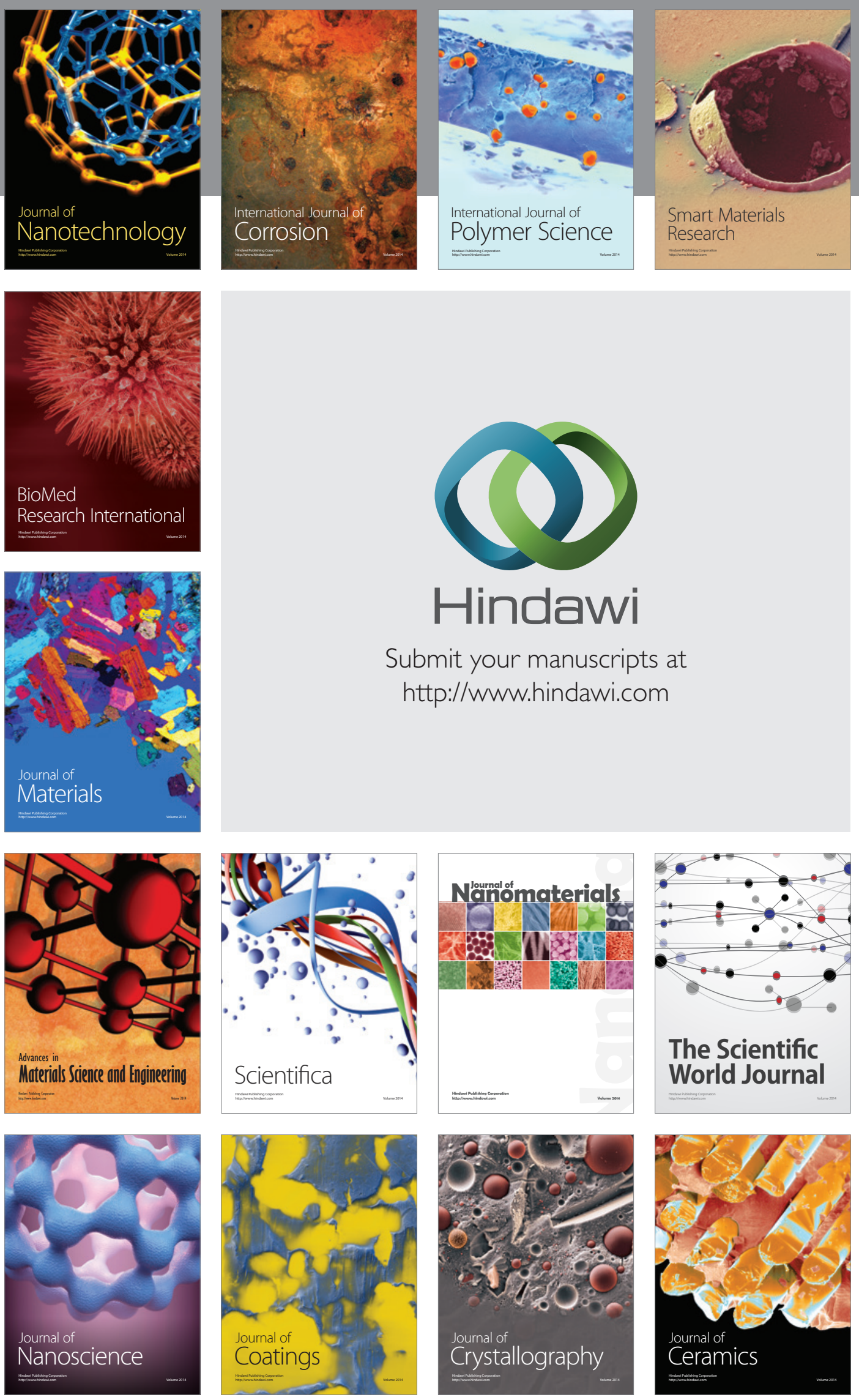

The Scientific World Journal

Submit your manuscripts at

http://www.hindawi.com

\section{World Journal}

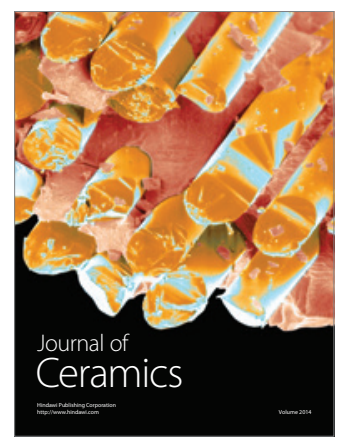

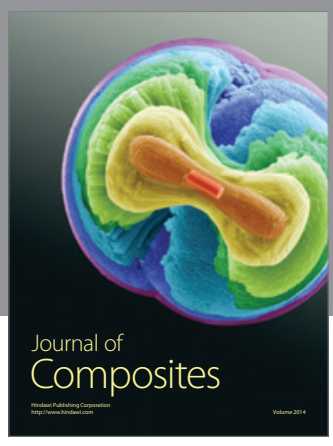
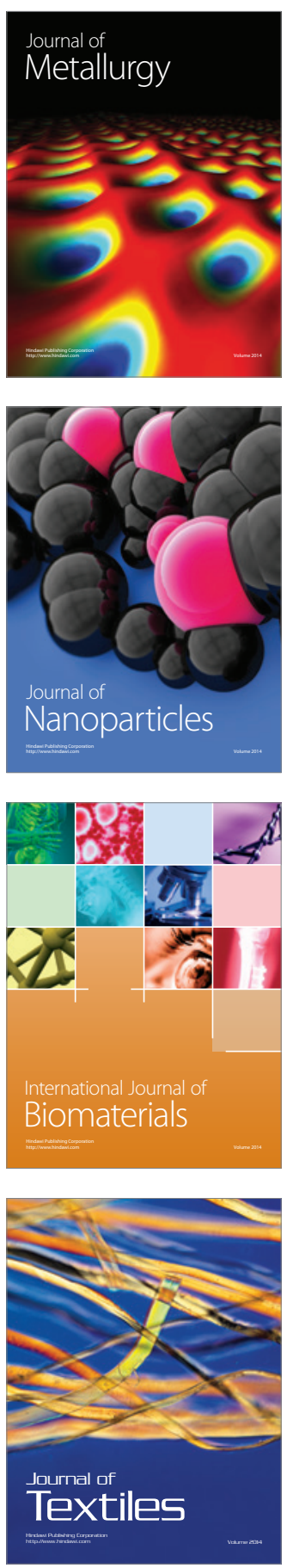